\title{
Research on Rock Resistant Coefficient in Lining Tunnels Based on the Generalized Hoek-Brown Failure Criterion
}

\author{
Shiyue Zhang $\mathbb{D}^{1,2}$ Ruiyuan Gao, ${ }^{3}$ Qingxiang Meng, ${ }^{2}$ and Xiaohu Zhang $\mathbb{D}^{4}$ \\ ${ }^{1}$ Shanghai Research Institute of Materials, Shanghai 200437, China \\ ${ }^{2}$ Key Laboratory of Ministry of Education for Geomechanics and Embankment Engineering, Hohai University, \\ Nanjing 210098, China \\ ${ }^{3}$ College of Construction Engineering, Jilin University, Changchun 130026, China \\ ${ }^{4}$ School of Civil Engineering, Guizhou University of Engineering Science, Bijie 551700, China \\ Correspondence should be addressed to Xiaohu Zhang; zhangxiaohucumtb@163.com
}

Received 12 January 2021; Revised 16 January 2021; Accepted 19 January 2021; Published 29 January 2021

Academic Editor: Feng Xiong

Copyright (C) 2021 Shiyue Zhang et al. This is an open access article distributed under the Creative Commons Attribution License, which permits unrestricted use, distribution, and reproduction in any medium, provided the original work is properly cited.

\begin{abstract}
Rock resistant coefficient is a key parameter in rock engineering and can reflect the resistance of surrounding rocks. According to the load-structure method, there are many different formulas in the determination of rock resistant coefficient using elasticity or plasticity theory. Based on the generalized Hoek-Brown failure criterion, this paper develops a closed-form formula for calculating the rock resistant coefficient. The sensibility of different parameters on the rock resistant coefficient is also analyzed. The fact shows that the formula is sensitive to $a, \sigma_{c}$, and $K_{d}$ comparing with $m_{b}$ and $s$ especially when they are in a low value, laying a foundation for the determination of rock resistant coefficient in similar lining tunnels.
\end{abstract}

\section{Introduction}

Geomaterials have an inherent ability of resisting load, and the ability can be quantified by a coefficient named as subgrade reaction coefficient in soil mechanics or rock resistant coefficient in rock mechanics. Rock resistant coefficient can reflect the physical and mechanical properties of surrounding rock, and it is a key parameter in the design of tunnel lining. During the designing of a project, there are many different methods in the determination of rock resistant coefficient [1-5]. Xu (1993) and Qian (1955) proposed their formulas using the elasticity theory $[6,7]$. Tu et al. (2008) develops a formula for calculating rock resistant coefficient for underwater tunnel based on Mohr-Column yield criterion [8]. Cai et al. (2007) gave a common method to calculate the resistance coefficient of adjoining rock for pressure tunnels by use of the unified strength theory [9]. Zhu et al. (2011) proposed a formula for calculating rock resistant coefficient based on SMP failure criteria [10].

However, there is not a formula based on the generalized Hoek-Brown failure criterion which has been widely used in rock engineering as a semiempirical method. Hoek and
Brown (1980) pointed out that the most commonly used criteria may not be valid for many types of rock, particularly for a jointed rock mass [11], For such rock, the Hoek-Brown failure criterion has been proved to be more suitable. For this consideration, an analytical solution of calculating the rock resistant coefficient with the generalized Hoek-Brown failure criterion is proposed in this paper.

\section{Generalized Hoek-Brown Criterion}

The Hoek-Brown failure criterion for rock masses is widely accepted and has been applied in a large number of rock engineering projects around the world. Hoek and Brown (1980) introduced their failure criterion in an attempt to provide input data for the analyses required for the design of underground excavations in hard rock [12-14]. The criterion was derived from the results of research on the brittle failure of intact rock by Hoek (1968) and on the modeling of jointed rock mass behaviour by Brown (1980). According to the latest modification, the generalized Hoek-Brown failure criterion is expressed as follows by Hoek et al. (2002) [15]: 


$$
\sigma_{1}=\sigma_{3}+\sigma_{c i}\left(m_{b} \frac{\sigma_{3}}{\sigma_{c i}}+s\right)^{a}
$$

where $\sigma_{1}$ and $\sigma_{3}$ are the major and minor principal stresses, respectively; $\sigma_{c i}$ is the uniaxial compressive strength of the intact rock; $m_{b}$ is a reduced value of the material constant $m_{i}$ and is given by

$$
m_{b}=m_{i}\left(\frac{\mathrm{GSI}-100}{28-14 D}\right) \text {, }
$$

where $s$ and $a$ are constants for the rock mass given by the following relationships:

$$
\begin{gathered}
s=\exp \left(\frac{\mathrm{GSI}-100}{9-3 D}\right), \\
a=\frac{1}{2}+\frac{1}{6}\left(e^{-\mathrm{GSI} / 15}-e^{-20 / 3}\right) .
\end{gathered}
$$

In the equations above, $m_{i}$ is a material constant for the intact rock, GSI is the Geological Strength Index of the rock mass, and $D$ is a rock mass disturbance factor. The ranges of GSI and $D$ are normally as follows: $10 \leq$ GSI $\leq 100$ and $0 \leq D$ $\leq 1$. The value of GSI $=10$ represents an extremely poor quality of rock mass, and $D=1$ corresponds to a highly disturbed rock mass. For GSI $=100$, the value of the constant $a$ is equal to 0.5 . In this case, the generalized failure criterion can degenerate to the original Hoek-Brown failure criterion.

\section{Analytical Solution for Rock Resistant Coefficient}

In order to obtain the rock resistant coefficient, a simplified model is shown in Figure 1. A circular opening excavated in a continuous, homogeneous, isotropic, initially elastic rock mass subjected to a hydrostatic stress $p_{0}$. The opening surface is subjected to an internal pressure $p$, and the material behavior used in this study is Hoek-Brown failure criterion. Under normal circumstances, there is a plastic zone surrounded by an elastic zone. For some special cases, there is a loose zone close to the lining, which can only transfer radial stress. In this paper, considering the timely support in most of practical engineering, the loose zone is neglected.

Assuming that the displacement of tunnel surface is $u_{0}$, according to the Winkler hypothesis, the rock resistant coefficient can be expressed as

$$
K=\frac{p}{u_{0}}
$$

3.1. Analytical Solutions of Stresses and the Radius of Plastic Zone. It is assumed that rock resistance is of radial uniform distribution around the tunnel. For the tunnel is long enough, it can be considered as an axisymmetric, plane strain problem. $\sigma_{1}$ and $\sigma_{3}$ are equal to circumferential and radial stresses $\sigma_{\theta}$ and $\sigma_{r}$, respectively. According to the generalized Hoek-Brown failure criterion, relationship between $\sigma_{r}$ and $\sigma_{\theta}$ can be written as follows:

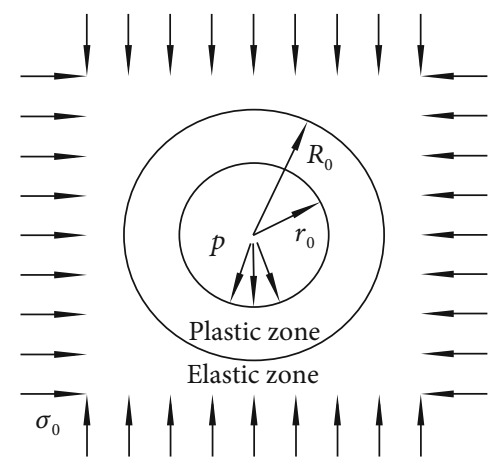

Figure 1: A simple calculation model of a tunnel.

$$
\sigma_{\theta}=\sigma_{r}+\sigma_{c i}\left(m_{b} \frac{\sigma_{r}}{\sigma_{c i}}+s\right)^{a} .
$$

The radial stress $\sigma_{R}$ at the interface of elastic and plastic zone may be obtained by combining the relationship between $\sigma_{r}$ and $\sigma_{\theta}$ in elastic and plastic state.

$$
2\left(\sigma_{0}-\sigma_{R}\right)=\sigma_{c i}\left(m_{b} \frac{\sigma_{R}}{\sigma_{c i}}+s\right)^{a} .
$$

For generalized Hoek-Brown failure criterion, it is impossible to give analytical solutions of Equation (6). Thus, an approximate closed-form solution for $\sigma_{R}$ can be obtained by the Newton-Raphson method. When $f(x)=0$, the corresponding formula is

$$
x_{k+1}=x_{k}-\frac{f\left(x_{k}\right)}{f^{\prime}\left(x_{k}\right)} .
$$

The initial value for $\sigma_{R 0}$ is determined when $a=0.5$.

$$
\sigma_{R 0}=\sigma_{0}+\frac{1}{8}\left[m_{b} \sigma_{c i}-\sqrt{\sigma_{c i}\left(m_{b}^{2} \sigma_{c i}+16 \sigma_{0} m_{b}+16 s \sigma_{c i}\right)}\right] .
$$

According Equation (5), the resulting solution $\sigma_{R}$ can be expressed as

$$
\sigma_{R}=\sigma_{R 0}+\frac{2\left(\sigma_{0}-\sigma_{R 0}\right)-\sigma_{c i} C_{1}{ }^{a}}{2+a m_{b} C_{1}{ }^{a-1}},
$$

where $C_{1}=m_{b}\left(\sigma_{R 0} / \sigma_{c i}\right)+s$.

In fact, the above approximate solution has been developed by Sofianos (2003).

In plastic zone, the stresses are governed by failure criterion. According to the equation of equilibrium in polar coordinates,

$$
\frac{d \sigma_{r}}{d r}+\frac{\sigma_{r}-\sigma_{\theta}}{r}=0 .
$$


Substitution of Equation (5) in Equation (10) leads to the following equation:

$$
\frac{d \sigma_{r}}{d r}=\frac{\sigma_{c i}}{r}\left(m_{b} \frac{\sigma_{r}}{\sigma_{c i}}+s\right)^{a}
$$

This is a simple differential equation with an initial condition of $\sigma_{\left.r\right|_{r=r_{0}}}=p$, the result solution may be expressed as follows:

$$
\sigma_{r}=\frac{\left[\left(\left(m_{b} / \sigma_{c i}\right) p+s\right)^{1-a}+(1-a) m_{b} \ln \left(r / r_{0}\right)\right]^{1 /(1-a)}-s}{m_{b} / \sigma_{c i}} .
$$

The circumferential $\sigma_{\theta}$ can be given by substituting Equation (12) in Equation (5).

The radius of plastic zones can be deprived by solving the equation obtained by substituting $r=R_{0}$ and $\sigma_{r}=\sigma_{R}$ in Equation (12). The solution is expressed as

$$
R_{0}=r_{0} \exp \left[\frac{\left(\left(m_{b} / \sigma_{c i}\right) \sigma_{R}+s\right)^{1-a}-\left(\left(m_{b} / \sigma_{c i}\right) p+s\right)^{1-a}}{(1-a) m_{b}}\right] .
$$

3.2. Analytical Solutions of Displacement. In the plastic region, total radial and tangential strains, $\varepsilon_{r}$ and $\varepsilon_{\theta}$, can be decomposed into elastic and plastic parts.

$$
\begin{gathered}
\varepsilon_{r}=\varepsilon_{r}^{e}+\varepsilon_{r}^{p}, \\
\varepsilon_{\theta}=\varepsilon_{\theta}^{e}+\varepsilon_{\theta}^{p} .
\end{gathered}
$$

The strains can be expressed in terms of inward radial displacement $u$ by Kyung and Yong (2006) et al. [16].

$$
\begin{aligned}
\varepsilon_{r} & =\frac{d u}{d r} \\
\varepsilon_{\theta} & =\frac{u}{r} .
\end{aligned}
$$

By using the small deformation theory and a linear flow rule, the plastic parts of radial and tangential strains may be related for the plane strain condition as

$$
\varepsilon_{r}^{p}+K_{d} \varepsilon_{\theta}^{p}=0
$$

For the Hoek-Brown failure criterion, the minimum of the dilation parameter is $K_{d}=1$ corresponding to a nondilating rock, while the maximum practical value is assumed to be equal to $K_{d}{ }^{\text {assoc }}$ which corresponding to the associated plasticity at $r=R_{0}$, the expression is given by Brown et al. (1983) [17].

$$
K_{d}^{\text {assoc }}=1+\frac{m_{b}}{2 \sqrt{\left(m_{b} \sigma_{R} / \sigma_{c i}\right)+s}} .
$$

Combing Equations (14)-(17) to Equation (18), the following differential equation can be expressed as

$$
\frac{d u}{d r}+K_{d} \frac{u}{r}=\varepsilon_{r}^{e}+K_{d} \varepsilon_{\theta}^{e}
$$

Equation (20) can be solved by using the following boundary condition for the radial displacement $u_{R}$ at the elastic plastic interface:

$$
u_{R}=R_{0}\left(\frac{1+v}{E}\right)\left(\sigma_{0}-\sigma_{R}\right)
$$

where $E$ is Young's modulus and $v$ is Poisson's ratio of the rock mass.

The solution of Equation (20) can be expressed as follows by Sharan (2008) [18]:

$$
u=r^{-K_{d}} \int_{R}^{r} r^{-K_{d}}\left(\varepsilon_{r}^{e}+K_{d} \varepsilon_{\theta}^{e}\right) d r+u_{R}\left(\frac{R_{0}}{r}\right)^{K_{d}},
$$

and $\varepsilon_{r}^{e}$ and $\varepsilon_{\theta}^{e}$ are expressed as

$$
\begin{aligned}
& \varepsilon_{r}^{e}=\frac{1+v}{E}\left[(1-2 v) C+\frac{D}{r^{2}}\right], \\
& \varepsilon_{\theta}^{e}=\frac{1+v}{E}\left[(1-2 v) C-\frac{D}{r^{2}}\right],
\end{aligned}
$$

where

$$
\begin{gathered}
C=\frac{\left(\sigma_{R}-\sigma_{0}\right) R_{0}^{2}-\left(p-\sigma_{0}\right) r_{0}^{2}}{R_{0}^{2}-r_{0}^{2}}, \\
D=\frac{R_{0} r_{0}\left(p-\sigma_{R}\right)}{R_{0}{ }^{2}-r_{0}{ }^{2}}
\end{gathered}
$$

The integration of Equation (22) can lead to an expression for the radial displacement in the plastic region as

$$
u=\frac{1+v}{E} r^{-K_{d}}\left[C(1-2 v)\left(R_{0}^{K_{d}+1}-r^{K_{d}+1}\right)-D\left(R_{0}^{K_{d}-1}-r^{K_{d}-1}\right)\right]+u_{R}\left(\frac{R_{0}}{r}\right)^{K_{d}} .
$$

3.3. Determination of Rock Resistant Coefficient. The radial displacement at the tunnel surface can be given when $r=r_{0}$.

$$
u_{0}=\frac{1+v}{E} r_{0}{ }^{-K_{d}}\left[C(1-2 v)\left(R_{0} K_{d}+1-r_{0}{ }^{K_{d}+1}\right)-D\left(R_{0}{ }^{K_{d}-1}-r_{0}{ }^{K_{d}-1}\right)\right]+u_{R}\left(\frac{R_{0}}{r_{0}}\right)^{K_{d}} .
$$

Substituting Equation (26) into Equation (4), the rock resistant coefficient can be expressed as 
TABLE 1: Basic parameters of the generalized Hoek-Brown criterion used for example study.

\begin{tabular}{lcccccccc}
\hline Rock type & Quality of rock mass & $\mathrm{GSI}$ & $\sigma_{c}(\mathrm{MPa})$ & $E(\mathrm{GPa})$ & $v$ & $a$ & $m$ & $s$ \\
\hline $\mathrm{A}$ & Very good & 75 & 150 & 42 & 0.2 & 0.5 & 10.2 & 0.062 \\
$\mathrm{~B}$ & Average & 50 & 80 & 9 & 0.25 & 0.51 & 2.01 & 0.0039 \\
$\mathrm{C}$ & Very poor & 30 & 20 & 1.4 & 0.3 & 0.52 & 0.657 & 0.0004 \\
$\mathrm{D}$ & Very poor & - & 30 & 38.0 & 0.3 & 0.3 & - & 0.55 \\
$\mathrm{E}$ & Very poor & 10 & 5 & 0.224 & 0.3 & 0.585 & 0.402 & 0.0000454 \\
\hline
\end{tabular}

TABLE 2: The parameters of reference state.

\begin{tabular}{lcccccccccc}
\hline$E(\mathrm{GPa})$ & $v$ & $\sigma_{0}(\mathrm{MPa})$ & $p(\mathrm{MPa})$ & $r_{0}(\mathrm{~m})$ & $\sigma_{c}(\mathrm{MPa})$ & $K_{d}$ & $m_{b}$ & $s$ & $a$ & $K(\mathrm{MPa} / \mathrm{m})$ \\
\hline 9 & 0.25 & 20 & 2 & 3 & 80 & 1.2 & 2 & 0.003 & 0.5 & 245.8 \\
\hline
\end{tabular}

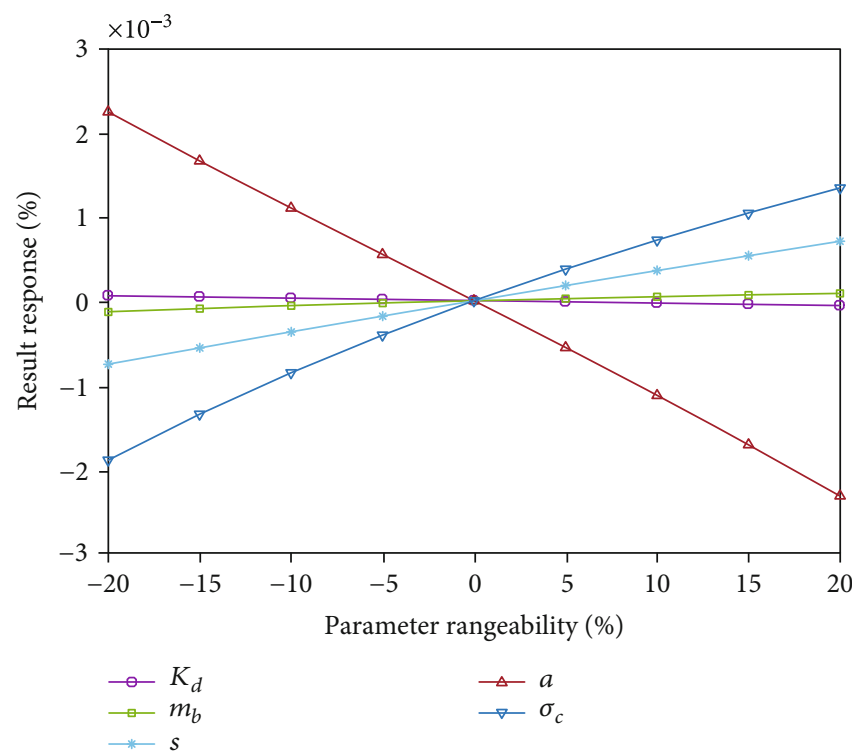

(a) Good quality rock

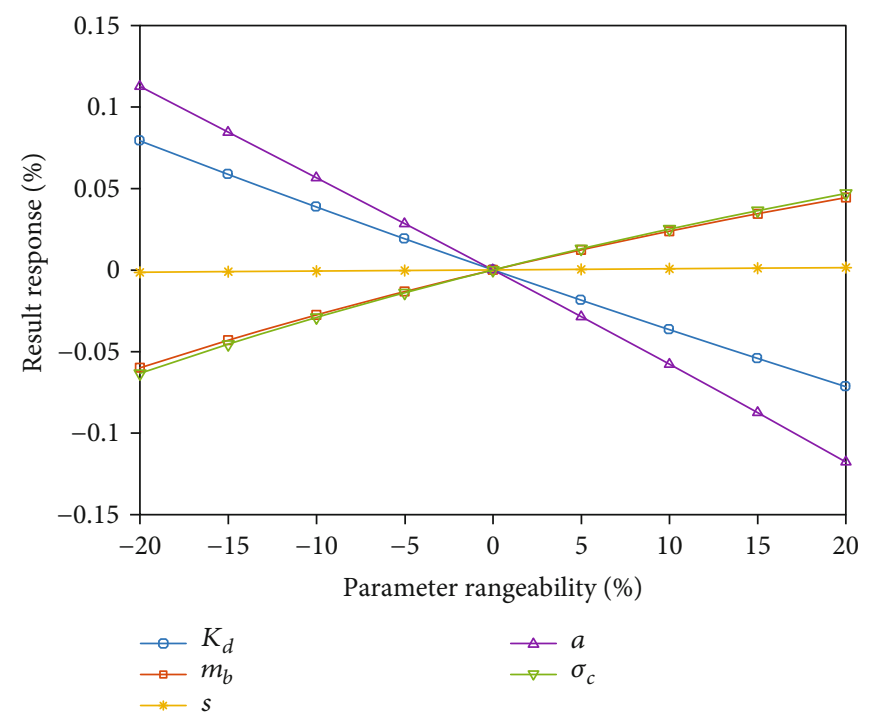

(b) Average quality rock

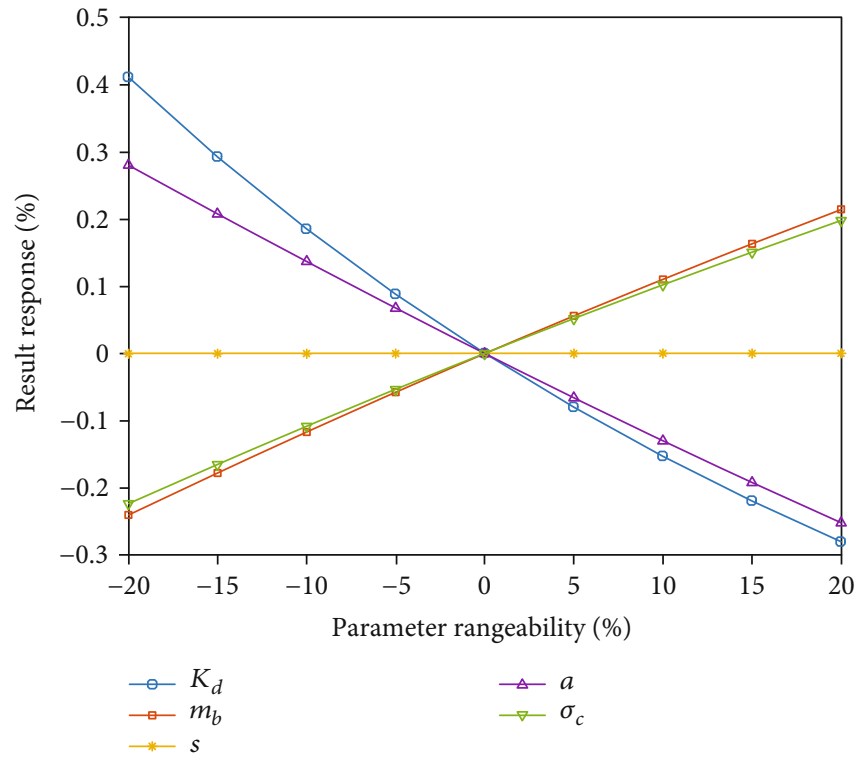

(c) Poor quality rock

FIGURE 2: Sensitivity of mechanical parameters on rock resistant coefficient. 


$$
K=\frac{p}{\left\{((1+v) / E) r_{0}{ }^{-K_{d}}\left[C(1-2 v)\left(R_{0} K_{d}+1-r_{0} K_{d}+1\right)-D\left(R_{0} K_{d}^{-1}-r_{0} K_{d}^{-1}\right)\right]+u_{R}\left(R_{0} / r_{0}\right)^{K_{d}}\right\}} .
$$

\section{Parameter Sensitivity Analysis}

In order to illustrate the effects of different rock parameters of the generalized Hoek-Brown failure criterion on the rock resistant coefficient $K$, the sensibility study will be presented. Zhang and Zhu (1993) presented a method in sensitivity analysis [19]. There is a system $F=f\left(x_{1}, x_{2}, \cdots \cdots, x_{n}\right)$, where $x_{i}(i=1,2, \cdots \cdots, n)$ is the parameter of this system. Considering a reference state $X^{*}=\left(x_{1}{ }^{*}, x_{2}{ }^{*}, \cdots \cdots, x_{n}{ }^{*}\right)$, with a character of $F^{*}=f\left(X^{*}\right)$, let each parameter changed in its range, the tendency, and degree of the difference between $F$ and $F^{*}$ is sensitivity analysis. For a parameter $x_{i}{ }^{*}$, the sensitivity function can be written as

$$
a\left(x_{i}^{*}, \Delta x_{i}\right)=\frac{\left|\Delta F / F^{*}\right|}{\left|\Delta x_{i} / x_{i}^{*}\right|} .
$$

According to the properties, data of rocks in underground opening mostly taken from the literatures by Sofianos (2003), Hoek and Brown (1997), and Canranza (2004) [20-22], the adopted parameters for the example study cover a wide range, and they are presented in Table 1.

According to Table 1 , the ranges of different parameters are $E=0.22-42 \mathrm{GPa}, v=0.2-0.3, \sigma_{c}=5-150 \mathrm{MPa}, m_{b}=$ $0.5-16, s=0.0000454-0.062$, and $a=0.5-0.585$. In order to analyze the sensitivity of different parameters, reference parameters can be assumed in Table 2 .

In fact, the sensitivity of $\sigma_{0}, p, E, r_{0}$, and $v$ is simple and is of no difference comparing to other failure criterions such as Mohr-Column. In this paper, we focus on the characteristics of parameters in generalized Hoek-Brown failure criterion.

For the dilation parameter $K_{d}$, it ranges from 1 to $K_{d}^{\text {assoc }}$. In the reference state, the maximum of $K_{d}$ can be calculated as 3.72. Then, the relationship of dilation parameter $K_{d}$ and rock resistant coefficient $K$ can be seen in Figure 2. According to Equation (27), the sensitivity function of dilation parameter $K_{d}$ was drawn in Figure 2. Using the similar method, sensitivity factors of other parameters $m_{b}, s$, and $a$ can be obtained.

Figure 2 shows the effects of different parameters on rock resistant coefficient $K$, the results show that rock resistant coefficient $K$ increases with $m_{b}$ and $\sigma_{c}$, while decreasing with $a$ and $K_{d}$. For parameters $s$, the range of rock resistant coefficient is very small. It changes a little big with a fluctuation of parameters $K_{d}$ and $a$. The relation between $K$ and $K_{d}$ is homogeneous; however, the relation between $K$ and $\sigma_{c}$ is heterogeneous. In the design of a tunnel, we need to pay more attention to $a, K_{d}, \sigma_{c}$, and $m_{b}$; also, it is very important to determine the range of different parameters. According to the equations of different parameters in the generalized Hoek-Brown failure criterion, it can be concluded that the sensitivity of rock resistant coefficient has close relationship with rock quality [23-25]. When the rock quality is good, the variability of rock resistant coefficient is small. On the contrary, it is very sensitive when the rock quality is poor, which means that a more accurate geology analysis is in demand. This is consistent with the engineering practice.

\section{Conclusions}

Rock resistant coefficient is a key parameter in the design of underground structures. Based on the generalized HoekBrown failure criterion, this paper develops a closed-form formula for calculating the rock resistant coefficient, and some useful conclusions are drawn as follows:

(1) A new formula of rock resistant coefficient is proposed in closed form, and this formula is more suitable for a jointed rock mass than other formulas

(2) According to the sensibility study of parameters, it can be concluded that the sensitivity factor of $a, \sigma_{c}$, and $K_{d}$ is bigger than $m$ and $s$

(3) Sensitivity of rock resistant coefficient has close relationship with rock quality; all these parameters except $s$ are highly sensitive when the rock quality is poor, which lays a foundation for the determination of rock resistant coefficient in similar lining tunnels

\section{Data Availability}

The data are available and explained in this article; readers can access the data supporting the conclusions of this study.

\section{Disclosure}

I would like to declare on behalf of my co-authors that the work described is original research and has not been previously published.

\section{Conflicts of Interest}

Authors declare no conflict of interest.

\section{Authors' Contributions}

The manuscript is approved by all authors for publication.

\section{Acknowledgments}

The authors gratefully acknowledge the funding provided by the National Natural Science Foundation of China (51709089), Guizhou Provincial Science and Technology Program ([2017]1062), and Guizhou Provincial Science and technology ([2015]7592). 


\section{References}

[1] Z. Li, S. Liu, W. Ren, J. Fang, Q. Zhu, and Z. Dun, "Multiscale laboratory study and numerical analysis of water-weakening effect on shale," Advances in Materials Science and Engineering, vol. 2020, Article ID 5263431, 14 pages, 2020.

[2] Q. Meng, H. Wang, M. Cai, W. Xu, X. Zhuang, and T. Rabczuk, "Three-dimensional mesoscale computational modeling of soil-rock mixtures with concave particles," Engineering Geology, vol. 277, article 105802, 2020.

[3] Z. G. Tao, C. Zhu, M. C. He, and M. Karakus, "A physical modeling-based study on the control mechanisms of Negative Poisson's ratio anchor cable on the stratified toppling deformation of anti-inclined slopes," International Journal of Rock Mechanics and Mining Sciences, vol. 138, p. 104632, 2021.

[4] Y. Wang, B. Zhang, S. H. Gao, and C. H. Li, "Investigation on the effect of freeze-thaw on fracture mode classification in marble subjected to multi-level cyclic loads," Theoretical and Applied Fracture Mechanics, vol. 111, p. 102847, 2021.

[5] Y. Wang, W. K. Feng, R. L. Hu, and C. H. Li, "Fracture evolution and energy characteristics during marble failure under triaxial fatigue cyclic and confining pressure unloading (FC$\mathrm{CPU})$ conditions," Rock Mechanics and Rock Engineering, pp. 1-20, 2020.

[6] Z. Y. Xu, Rock Mechanics, China Water Power Press, Beijing, 1993.

[7] L. X. Qian, "Calculation method of elastic resistant co-efficient "K" in hydraulic pressure tunnel," China Civil Engineering Journal (Tu Mu Gong Cheng Xue Bao), vol. 2, no. 4, pp. 369380, 1955.

[8] Z.-r. Tu, Q. Yang, Q.-m. Shen, and X.-w. Wang, "Determination of rock resistant coefficient based on Mohr-Coulomb criterion for underwater tunnel," Journal of Zhejiang UniversitySCIENCE A, vol. 9, no. 9, pp. 1239-1244, 2008.

[9] C. A. I. Xiao-hong, C. A. I. Yong-bin, C. A. I. Yong-ping, and K. A. N. G. Huai-peng, "Calculation of resistance coefficient of adjoining rock for pressure tunnels considering effect of intermediate principal stress," Chinese Journal of Geotechnical Engineering(Yan Tu Gong Cheng Xue Bao), vol. 29, no. 7, pp. 1004-1008, 2007.

[10] J. M. Zhu, X. P. Peng, and J. H. Xu, "Determination of rock resistant coefficient in lining tunnels based on SMP failure criterion," Chinese Journal of Geotechnical Engineering(Yan Tu Gong Cheng Xue Bao), vol. 33, no. 5, pp. 700-704, 2011, (in Chinese).

[11] E. Hoek and E. T. Brown, "Empirical strength criterion for rock masses : Hoek, E; Brown, E T J Geotech Engng Div ASCE, V106, NGT9, Sept 1980, P1013-1035," International Journal of Rock Mechanics and Mining Sciences \& Geomechanics Abstracts, vol. 18, no. 2, p. 23, 1981.

[12] E. Hoek and E. T. Brown, Underground excavation in rock, London Institution of Mining and Metallury., 1980.

[13] E. Hoek, "Brittle failure of rock," in Rock Mechanics in Engineering Practice, K. G. Stagg and O. C. Zienkiewicz, Eds., pp. 99-124, Wiley, London, 1968.

[14] Q. X. Meng, H. L. Wang, W. Y. Xu, and Y. L. Chen, "Numerical homogenization study on the effects of columnar jointed structure on the mechanical properties of rock mass," International Journal of Rock Mechanics and Mining Sciences, vol. 124, article 104127, 2019.
[15] E. Hoek, C. Carranza-Torres, and B. Corkum, "Hoek-Brown criterion - 2002 edition," Proceedings of NARMS-TAC Conference, 2002, pp. 267-273, Toronto, 2002.

[16] H. P. Kyung and J. K. Yong, "Analytical solution for a circular opening in an elastic-brittle-plastic rock," International Journal of Rock Mechanics and Mining Sciences, vol. 43, no. 4, pp. 616-622, 2006.

[17] E. T. Brown, J. W. Bray, B. Ladanyi, and E. Hoek, "Ground response curves for rock tunnels," Journal of Geotechnical Engineering, vol. 109, no. 1, pp. 15-39, 1983.

[18] S. K. Sharan, "Analytical solutions for stresses and displacements around a circular opening in a generalized HoekBrown rock," International Journal of Rock Mechanics and Mining Sciences, vol. 45, no. 1, pp. 78-85, 2008.

[19] Z. Guang and W. Zhu, "Parameter sensitivity analysis and optimizing for test programs," Rock and soil mechanics, vol. 14, no. 1, pp. 51-58, 1993.

[20] A. I. Sofianos, "Tunnelling Mohr-Coulomb strength parameters for rock masses satisfying the generalized Hoek-Brown criterion," International Journal of Rock Mechanics \& Mining Sciences, vol. 40, no. 3, pp. 435-440, 2003.

[21] E. Hoek and E. T. Brown, "Practical estimates of rock mass strength," International Journal of Rock Mechanics and Mining Sciences, vol. 34, no. 8, pp. 1165-1186, 1997.

[22] C. Carranza-Torres, "Elasto-plastic solution of tunnel problems using the generalized form of the Hoek-Brown failure criterion," International Journal of Rock Mechanics and Mining Sciences, vol. 41, no. 3, pp. 480-481, 2004.

[23] D. W. Yin, S. J. Chen, Y. Ge, and R. Liu, "Mechanical properties of rock-coal bi-material samples with different lithologies under uniaxial loading," Journal of Materials Research and Technology, vol. 10, pp. 322-338, 2021.

[24] C. Zhu, M. C. He, Q. Yin, and X. H. Zhang, "Numerical simulation of rockfalls colliding with a gravel cushion with varying thicknesses and particle sizes," Geomechanics and Geophysics for Geo-Energy and Geo-Resources, vol. 7, no. 1, p. 11, 2021.

[25] L. L. Yang, W. Y. Xu, Q. X. Meng, and R. B. Wang, "Investigation on jointed rock strength based on fractal theory," Journal of Central South University, vol. 24, no. 7, pp. 1619-1626, 2017. 